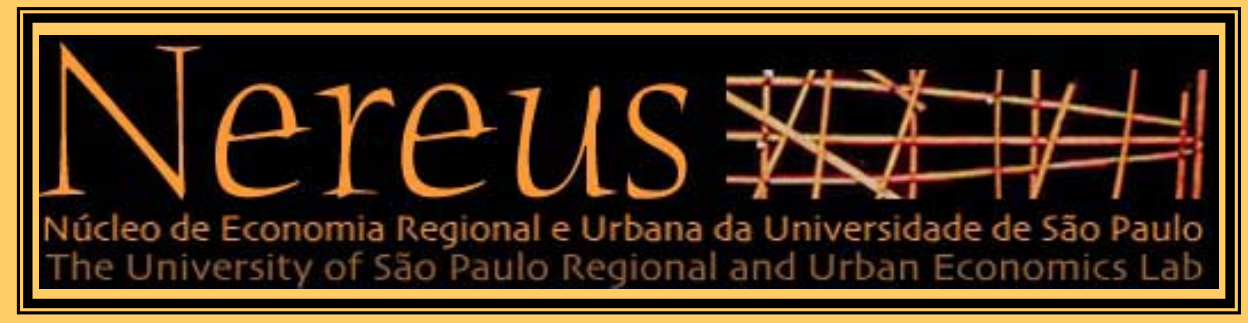

\title{
LOCATION AND REGIONAL INCOME DISPARITY DYNAMICS: THE BRAZILIAN CASE
}

Raul Silveira-Neto

Carlos R. Azzoni

TD Nereus 01-2005

São Paulo 2005 


\title{
Location and Regional Income Disparity Dynamics: the Brazilian Case*
}

\author{
Raul Silveira-Neto ${ }^{1}$, Carlos R. Azzoni ${ }^{2}$
}

\begin{abstract}
In this paper we provide evidence on the importance of location for the growth of per capita income of Brazilian states over the period 1985-2001. The study presents strong evidence of spatial dependence, and that regional inequality reduction occurred simultaneously with increasing spatial autocorrelation. The analysis of local indicators of spatial association confirmed that conclusion, showing the existence of two geographical clusters, one of low income states in the Northeast and North regions, and another of rich states in the Southeast and South regions. The low value for the convergence coefficient, in conjunction with the strong influence of shocks in the residuals, indicate the existence of a very sensible dynamic of convergence across Brazilian states, what helps explaining the well documented persistence in regional income disparities in Brazil. After conditioning on other important variables that could affect growth, however, spatial dependence disappears. We have thus identified two potential channels through which the strong spatial dependence in the process of convergence of per capita income of Brazilian states occurs.
\end{abstract}

JEL: R110; R120; R150

Keywords: Brazil, Income Convergence, Geographical Influences, Spatial Dependence

\section{Introduction}

Barro and Sala-I-Martin (1991) have broadened the interest on the Neoclassical Growth Model property of convergence by changing the focus from international to regional economic unities within countries. This change in perspective allowed for the consideration of the actions of neighbors, the geographic influences across these economic unities, and to explore the importance of these effects in the process of income convergence.

\footnotetext{
* Support from CNPq - Conselho Nacional de Pesquisa (Bolsa Produtividade), and Fipe - Fundação Instituto de Pesquisas Econômicas, is acknowledged.

${ }^{1}$ Assistant Professor of Economics, Federal University of Pernambuco, Brazil

${ }^{2}$ Professor of Economics, University of Sao Paulo, Brazil
} 
Growth correlation across neighbor economies seems to be quite common. Several models and empirical studies have shown that distance between regional economies directly affects economic growth. This can be in the attraction of foreign direct investment (Eaton and Tamura 1994), the transmission and absorption of technology (Jaffe et al. 1993; Eaton and Kortum 1994, 1996), the trade of goods and services (Frankel and Wei 1993; Frankel and Romer 1996), and labor migration (Braun 1993; Barro and Sala-I-Martin 1995). Neighboring economies tend to exhibit spatial correlation in variables that affect economic performance, such as weather, political and legal conditions, culture, etc. However, empirical evidence on the direct influence of such location effects has only recently begun to emerge. Although highly intuitive, the possibility of geographic spillovers affecting the growth dynamic of neighboring economies, and so the convergence process, have only recently been empirically explored, the pioneering work being attributed to Rey and Montouri (1999).

The purpose of this paper is to provide evidence on the importance of location for the growth of per capita income of Brazilian states. Regional per capita income disparities in Brazil are among the highest and more persistent in the world ${ }^{3}$, what makes this country an interesting case study for the problem. We first deal with the identification of spatial dependence in the process of income convergence across Brazilian states in the period 1985-2001, by considering potential spatial effects on the traditional unconditional convergence equation. We then offer evidence on the possible channels through which these spatial effects exert their influences.

In the next section, we review the literature on geographical location and growth. This is followed by an overview of growth and income patterns in Brazil. In section 3, we first use spatial statistics to provide evidence on the geographic clustering and convergence of per capita income across Brazilian states; then we investigate the influence of spatial dependence in the convergence process, and discuss the model specification to account for the spatial effects. Section 4 contains an investigation of

\footnotetext{
${ }^{3}$ For analysis and information on the Brazilian case, see Azzoni et all (2000); Azzoni (2001); Azzoni and Servo (2002); Baer (2001); Lall and Shalizi (2003); Mossi et al. (2003); Magalhães et al. (2005); Azzoni and Andrade (2005); Azzoni and Silveira-Neto (2005); Azzoni et all (2005). Shankar and Shah (2003) analyze the persistence of regional inequality in different countries, including Brazil.
} 
spatial dependence in the context of those spatial effects. The last section presents the conclusions of the study.

\section{Location and Growth: theories and evidence}

Several possible reasons may be put forward for the correlation of growth between neighboring economies. A trivial factor is related to the non-economic way the borders of different spatial units are defined: areas with similar geographical (physical and human) and economic background conditions are sometimes artificially split into different jurisdictions (municipalities, states, etc.). Since these jurisdictions belong to a similar socio-economic environment, intense interaction among them is to be expected. Another aspect is that interaction between neighboring economies, through the flow of goods, factors and information, is easier and faster, due to lower transportation costs. A third factor relates to the fact that neighboring economies tend to experience common shocks, such as wars, political instabilities or even weather-related events, such as droughts, similar rainfall patterns, etc., all of which can affect their economic performance. These factors could be responsible for the occurrence of spatial autocorrelation in important growth-related variables.

The formalization of such effects is, however, relatively recent. Chua (1993) presented an interesting model that explicitly incorporates regional investments in physical and human capital in the production function of a specific spatial unit within a region. His model is influenced by the pioneering works of Arrow (1962) and Romer (1986), on the importance of externalities resulting from technical progress that are not fully captured by private agents, and Lucas (1988), on the importance of externalities related to human capital. Chua showed that growth in spatial unit $i$ belonging to region $r$ depends on the magnitude of investments in human and physical capital occurring at the regional level. Goodfriend and McDermott (1998) explored the direct influence of technical progress in neighboring economies. They treat location as a key factor in the determination of the degree of income convergence in a growth model with technological spillovers. Barro and Sala-i-Martin (1997) proposed a model in which the growth of leading economies, based on the discovery of new products and new technologies, is 
diffused subsequently to other follower economies, thereby promoting their growth. In their model, per capita product growth $\left(g_{y}\right)$ around the steady state $(*)$ in the follower economy ( $i$ ) may be expressed by

$$
g_{y i}=g_{A j}-\mu\left[\log \left(\frac{y_{i} / y_{j}}{\left(y_{i} / y_{j}\right)^{*}}\right)\right],
$$

with $j$ indicating the leading economy, $A_{j}$ representing technical progress, and $\mu$ being a constant that is related to imitation costs. Accepting that there are locational spillovers implies that $\mu$ is dependent on the location of economies $i$ and $j$.

Some models examining imperfect markets and increasing returns to scale, without incorporating geographical effects, have also been used to point out the importance of spatial effects on growth. Murphy et al. (1989a; 1989b) proposed a model for a small economy in which the growth of an export-oriented leading sector generates a large enough internal market to make industrialization possible, thereby highlighting the importance of the location of such a small economy for growth. The well-known "big push" model emphasizes the importance of the simultaneous growth of all sectors in an economy. The same argument can be easily applied to small economies trading among themselves: they can experience simultaneous "big pushes", thus providing reciprocal markets and fostering their simultaneous growth (Moreno and Trehan, 1997).

Recent empirical evidence on the role of location in economic growth appears to be quite solid. Locational spillovers have been examined in the context of the adoption of new technologies (Case, 1992), knowledge spillovers (Jaffe et. al., 1993), expansion of regional road density (Ades and Glaeser, 1994), human and physical investment (Chua, 1993), growth of per capita income (Sala-i-Martin, 1995) and political instability and its negative impact on economic growth (Ades and Chua, 1997). Moreno and Trehan (1997) ascertained the influence of neighboring countries on growth, finding that this influence is not fully explained by common shocks and/or by trade flows between countries. Applying Moreno and Trehan's model to US states, European regions, and countries around the world, Attfield et al. (2000) found that spatially correlated growth is explained 
by regional dummies and initial incomes. That is, they found that geographical proximity per se does not matter. On the other hand, Adserà (2000) studied sectoral externality gains from concentration and diversity, and found that American states and metropolitan areas benefited significantly from a high level of economic activity in nearby areas. Finally, Rey and Montuori (1999) and Rey (2001), on income convergence in the U.S. at the state level, indicated that shocks in specific states affect neighboring states, leading to more complex transition convergence dynamics than when spatial effects are not considered.

In the case of Brazil, few studies have considered spatial effects in analyzing regional growth. Magalhães et al. (2005) dealt with yearly GDP data for states over the period 1970-1995, and found strong patterns of spatial correlation. They indicate that, although some convergence was taking place, it seems more a case of club convergence than a global convergence process. Taking a longer term perspective, Mossi et all (2003) used intradistribution dynamic tools based on Markov transition matrices and stochastic kernells for decade averages of state GDP over the period 1939-1998, and revealed the existence of two spatial clusters, a low-income cluster in the northeast of the country, and a high-income cluster in the southeast. Lall and Shalizi (2003) studied the contribution of location to regional economic growth across municipalities within the Northeastern region. They concluded that there are negative spatial externalities coming from productivity improvements in neighboring municipalities.

\section{Convergence, Geographic Clustering and Per Capita Income Dynamic in Brazil}

This section has two objectives. First, it provides an overview of growth and income distribution in Brazil for the period 1985 to 2001, then shows how important are spatial effects for per capita income inequality dynamic of Brazilian states.

\subsection{Spatial statistics evidence}


As described in Appendix 1, we have dealt with GDP data, at the state level. Map 1 shows that the regional distribution of per capita income in Brazil is highly uneven. The Southeastern states present higher income levels (darker colors); most of the Northeastern states present lower income levels. Income level differences are extremely high: the richest state of Sao Paulo has a per capita income level 6 times higher than the poorest Maranhão state. This situation has been relatively stable (Shankar and Shah, 2003; Magalhães et al. 2005). Map 2 shows that both the Central and some neighboring Northeastern states display higher growth rates.

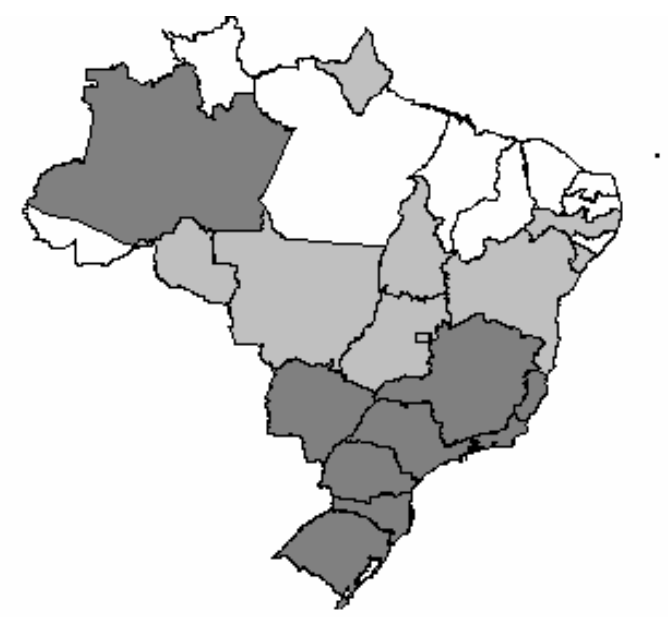

Map 1 - Per capita income of Brazilian states, 2001.

Darker color indicates higher income level.

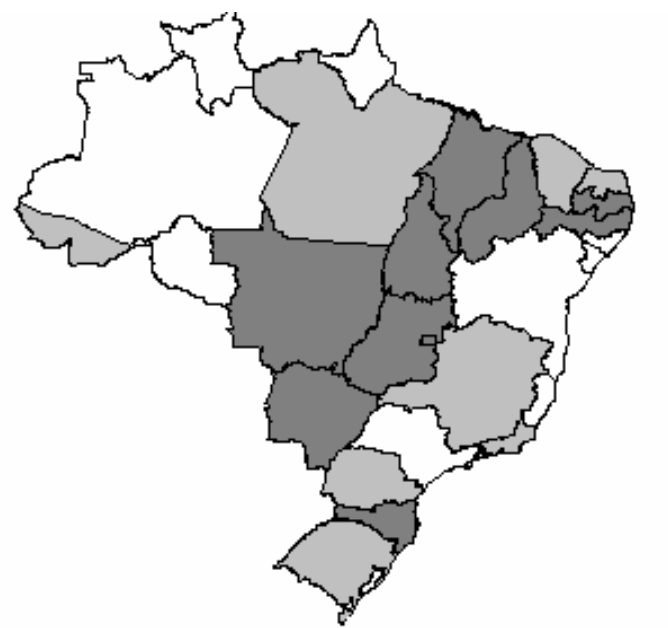

Map 2 - Growth of Per capita income of Brazilian states, 1985-2001. 
Darker color indicates higher growth.

Following Rey and Mountori (1999), the per capita income inequality dynamics across Brazilian states is analyzed with emphasis on geographical location. Spatial autocorrelation statistics and income dispersion indicators are initially computed, in order to see if the evolution of the later is conditioned by location; traditional growth equations are then estimated, considering different patterns of spatial influences on the dynamics of inequality.

Figure 1 presents the coefficient of variation (CV) of per capita income levels across states ( $\sigma$ - convergence), and Moran's I indicator of spatial correlation, which can be written as

$$
I_{t}=\left(\frac{n}{s_{0}}\right) \frac{\sum_{i=1}^{n} \sum_{j=1}^{n} w_{i j} x_{i, t} x_{j, t}}{\sum_{i=1}^{n} \sum_{j=1}^{n} x_{i, t} x_{j, t}},
$$

Where $n$ is the number of states (25); $w_{i j}$ is a binary elements (weights), $w_{i j}=1$ if states $i$ and $j$ have a common frontier, and $w_{i j}=0$ otherwise; $s_{0}$ is a scale factor equal to the sum of the elements of the transposed $\mathrm{W}$ matrix whose elements are the $w_{i j, s} ; x_{i t}$ is the natural logarithm of per capita income of state $i$ in year $t$.

The results in Figure 1 show some oscillations in the dispersion of the log of per capita income across Brazilian states before 1993, and a clear diminishing trend after that. They also show strong evidence of spatial dependence, since Moran's I is significant for all years. It is also noticeable that the reduction in income dispersion is associated to increasing spatial dependence. That is, regional inequality reduction occurred simultaneously with increasing spatial autocorrelation in Brazil, a result that is the opposite of the findings of Rey and Montouri, for American states. This result has important implications for the character of the observed reduction in inequality. It could be indicating either that inequality reduction is taking place more strongly among rich states and their neighbors, or that poor states and their neighbors are in a similar process of catching-up with the rich states. In the first case, a reduction in inequality in the 
vicinity of rich states would be observed; in the later, diminishing inequality among poor states would be the case.

Figure 1 - Income convergence and spatial autocorrelation

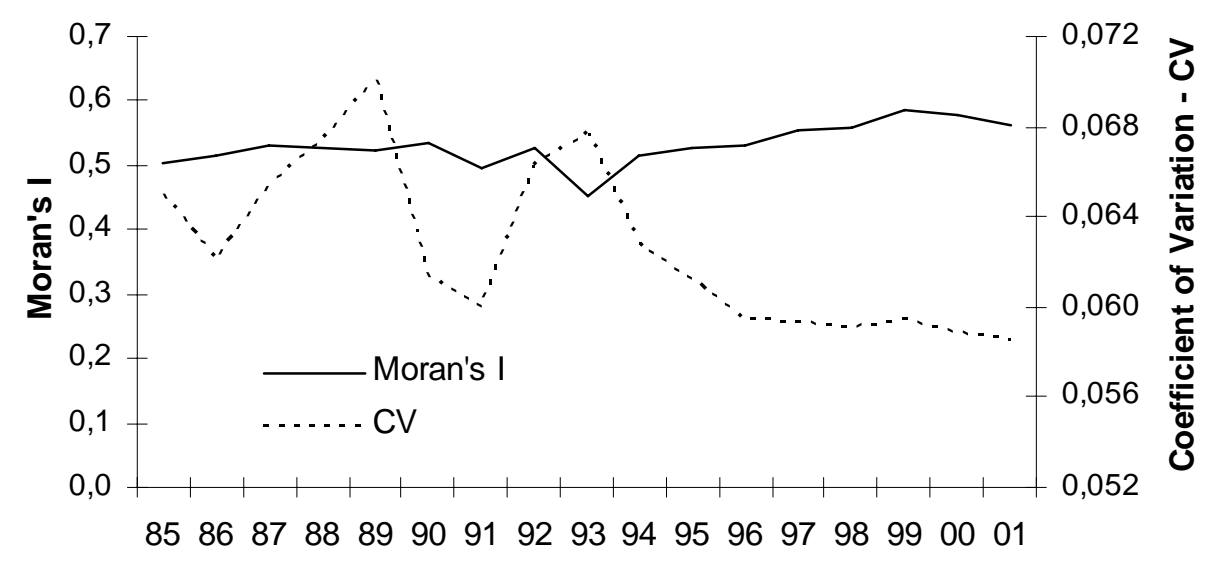

As a general statistic, Moran's I does not allow for the distinction among these two possible patterns of inequality reduction. Local indicators of spatial association ${ }^{4}$ are presented in maps 3 and 4. The results confirm the evidence of the two previous maps. There are two geographical clusters, one composed of low income states in the Northeast and North regions, and another, formed by states in the Southeast and South regions. Over the period, only two states changed their status, moving from the non-significant group towards the rich group (Mato Grosso do Sul, in the Center-West region, and Santa Catarina, in the Southern region); the number of states in the low income group remained the same.

${ }^{4}$ As presented by Anselin (1988), $I_{i, t}=\left(\frac{x_{i}}{m_{0}}\right) \sum_{j=1}^{n} w_{i j} x_{j, t}$, whit $m_{0}=\sum_{i}^{n} x_{i, t}^{2}$. 


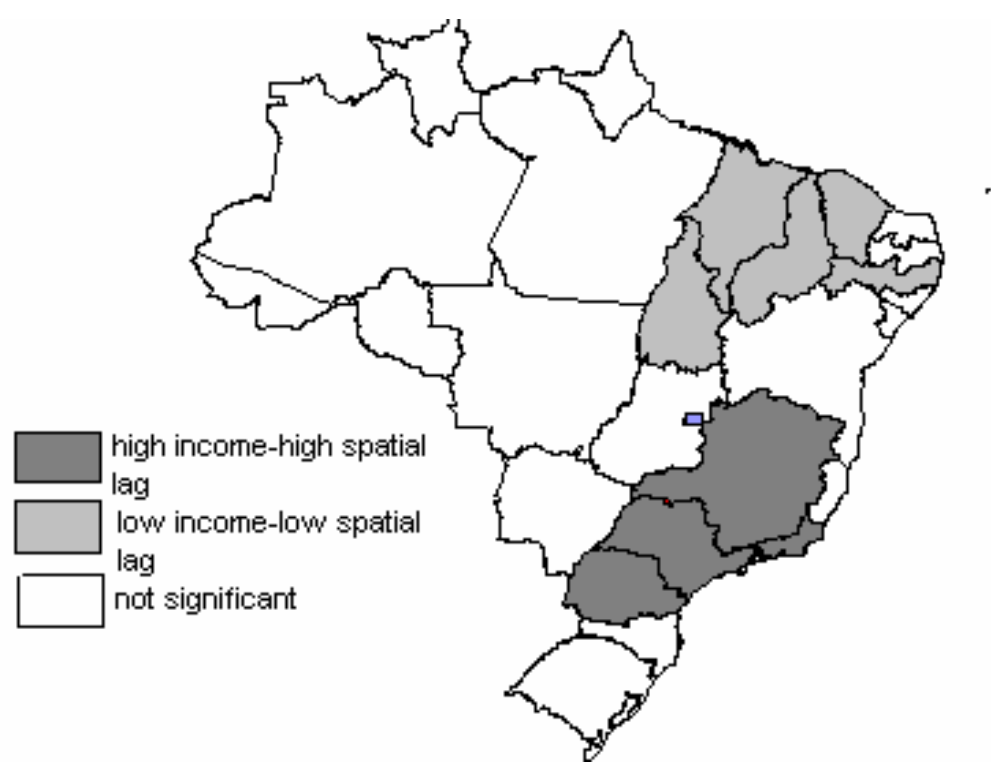

Map 3 - Local Moran statistics - per capita income, 1985

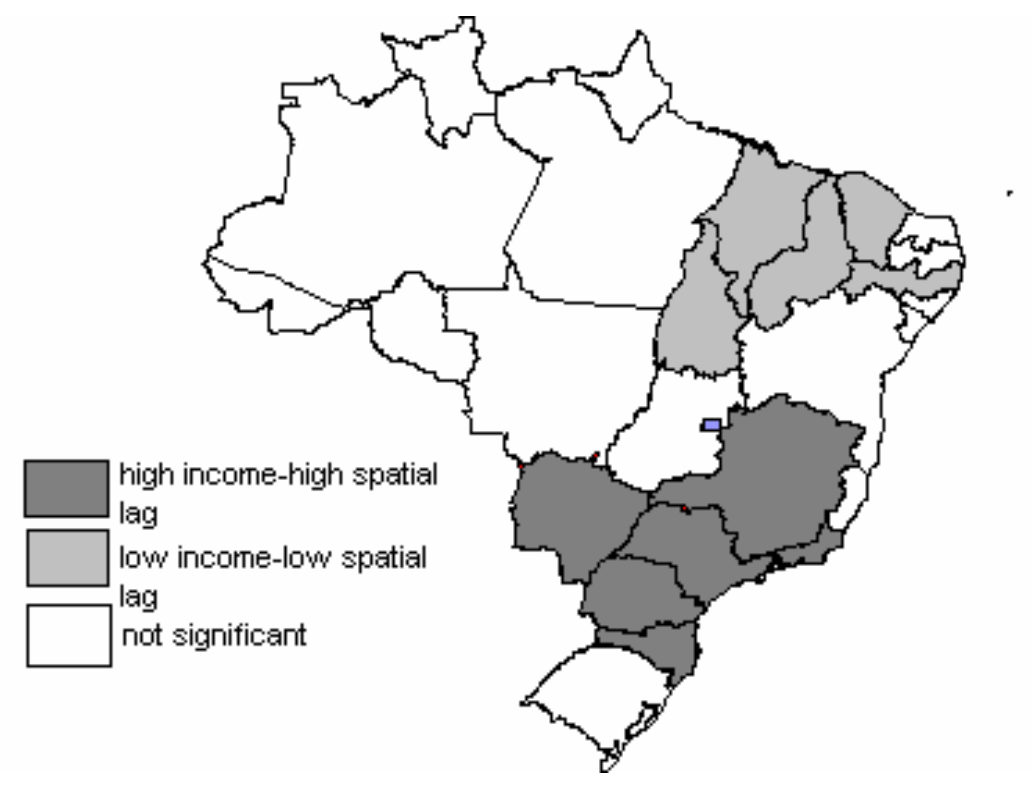

Map 4 - Local Moran statistics - per capita income, 2001

These results indicate that there is and important spatial rigidity in the distribution of per capita income across states in Brazil. Moreover, they suggest that the observed reduction in per capita income dispersion is associated with the reduction of inequality among rich states and their neighbors. 


\subsection{Econometric evidences}

In order to provide additional information on the dynamic pattern of income inequality among Brazilian states, and on the importance of location in determining that dynamic pattern, traditional convergence equations were estimated. Absolute convergence was estimated at first; tests were then applied to establish the importance of spatial conditionants; finally, conditional convergence was estimated, allowing for the assessment of the role of some important economic variables, such as education.

The following equation was estimated in the first stage:

$$
g_{i}=\alpha+\beta y_{0, i}+\varepsilon_{i}, \quad i=1, \ldots ., n
$$

Where $g_{i}$ is the growth in per capita income in state $i$ in the period 1985-2001; $y_{0, i}$ is the logarithm of the initial level of per capita income; $\alpha$ and $\beta$ are parameters to be estimated; $\varepsilon_{i}$ is $N\left(0, \sigma^{2}\right)$.

The above estimation of the parameters can be biased or inefficient, depending on the kind of spatial dependence observed. This implies that it is necessary not only to correctly describe the convergence process, but also to determine the existence of convergence itself. Following Rey and Mountouri (1999), we have then first estimated the spatial error model, in which spatial dependence affects the error term. Formally:

$$
g=\alpha+\beta y_{0}+\varepsilon, \quad \text { where } \quad \varepsilon=\lambda W \varepsilon+\mu
$$

Now $g$ is the vector of per capita income growth of states, $W \varepsilon$ is the spatial lag of the error term, and $\mu$ follows a normal distribution $\mathrm{N}(0, \sigma 2)$. This kind of spatial dependence can be present in the absence of spatially related variables affecting the income grow of the states. Note that such factors can be economic or, as pointed out by Lall and Shalizi (2003), social, cultural or geographical. The presence of such a kind of dependence would lead to unbiased, but inefficient estimates. 
We have also estimated a spatial lag model, which considers that the observed spatial dependence is created by the actual interaction among the growth of the states. Specifically:

$$
g=\alpha+\beta y_{0}+\rho W g+\varepsilon
$$

where $W g$ is a vector of "spatially lagged" per capita income growth, that is, the average per capita income growth of neighboring states. This type of spatial dependence can be observed, for example, if there are pure spillovers, as considered by Griliches (1992), a situation in which knowledge transmission occurs without economic transactions. It can also be observed in the presence of rent spillovers, in which case the effects of an innovation on productivity growth are not reflected in the price of the good in which the innovation is embodied (Griliches, 1992). As pointed out by Anselin (1988), this kind of spatial dependence leads to biased estimates when using OLS estimator ${ }^{5}$.

The third case we have considered assumes the presence of spatial dependence in the independent variable, $y$, and is referred to as the spatial cross-regressive model. Formally:

$$
g=\alpha+\beta y_{0}+\phi W y_{0}+\varepsilon
$$

Now spatial dependence appears in the initial per capita income of the states, suggesting that initial development levels of neighboring states are related. Differently from the two other cases, here there are no immediate econometric problems by using the OLS estimator.

\footnotetext{
${ }^{5}$ This comes from the fact that $\mathrm{E}\left((W g)^{\prime} . \varepsilon\right)=\mathrm{E}\left\{\left[W(\mathrm{I}-\rho W)^{-1} \varepsilon\right]^{\prime} . \varepsilon\right\}=0$ only if $\rho=0$.
} 
The results of estimation of the parameters of equation (3) by OLS are presented in Table 1 , and confirm the $\sigma$-convergence trend pointed out before. The estimated speed of convergence, however, is very low $(0.05 \%)$, much lower than the $1.9 \%$ obtained for American states by Rey and Montouri (1999). This low speed of convergence is compatible with the long-lasting history of regional disparities in Brazil. It is also consistent with the similarity between the scatterplots for 1985 and 2001 presented in figures 2 and 3. As for spatial dependence, the Moran's $I$ statistic is significant at the $5.2 \%$ level, and the robust LM error test is significant at the $10.2 \%$ level. For the case of $\mathrm{LM}$ robust lag test, it is significant only at the $18.8 \%$ level. Thus, one can not reject the hypothesis of the existence of spatial dependence in the income inequality dynamics of Brazilian states 6 .

\section{Table 1 - Unconditional convergence. The dependent variable is the growth in per capita income.}

\begin{tabular}{lcc}
\hline & Coefficient & p-value \\
\hline$\alpha$ & 0.075 & $(0.018)$ \\
$\beta$ & -0.008 & $(0.041)$ \\
Adjusted $\mathrm{R}^{2}$ & 0.1682 & \\
AIC & -160.098 & \\
Convergence rate & 0.0005 & \\
\hline
\end{tabular}

Diagnosis for spatial dependence

\begin{tabular}{lll}
\hline Moran's I & 1.938 & $(0.052)$ \\
Robust LM (error) & 2.662 & $(0.102)$ \\
Robust LM (lag) & 1.726 & $(0.188)$ \\
\hline
\end{tabular}

Diagnosis for heteroskedascticity

\begin{tabular}{lll}
\hline Breusch-Pagan test & 0.0126 & $(0.910)$ \\
Koenker-Bassett test & 0.0164 & $(0.898)$ \\
\hline
\end{tabular}

Obs.: OLS method applied. The convergence rate is obtained using $\theta=\ln (\beta+1) /-\mathrm{k}$, with $\mathrm{k}$ being the number of years in the period.

\footnotetext{
${ }^{6}$ The spatially adjusted Breusch-Pagan and the Koenker-Basset tests indicate that there are no heteroskedasticity problems.
} 
When compared to the Robust LM spatial lag, the Robust LM spatial error statistics was found significant at a lower level. Thus, between the Spatial Error Model and the Spatial Lag Model, we should choose the first. The results on Table 2 reinforce the preference for adopting the Maximum Likelihood (ML) method for estimating the three models.

Table 2 presents the results of estimation of the parameters of spatial models represented by equations (4), (5) and (6).

Only the estimate of the parameter $\lambda$ of the spatial error model is statistically significant at standard levels. If we use the Akaike Information Criteria (AIC) and the Shawrz Criteria (SC) to select the models, we also choose the spatial error model for it presents the best fit, confirming previous evidence from the LM robust tests ${ }^{7}$. The convergence coefficient does not change significantly, but is important to point out the economic meaning and the high value of the coefficient of the spatial lag of the error term. As it was first noted by Rey and Montouri (1999), this result implies that the spatial autocorrelation in the initial income levels, together with the convergence hypothesis, do not entirely explain the spatial autocorrelation in growth rates. Rey and Montouri (1999) have also found that the best fit is provided by the spatial error model, with an estimated spatial coefficient of 0.158 , which amounts to just $39 \%$ of the value we have found for the Brazilian case. The result thus suggests stronger effects of spatial shocks in the dynamic of growth of per capita income in the Brazilian case. If we consider the low value of the convergence coefficient, in conjunction with this strong influence of shocks in the residuals, the net result points to the existence of a very sensible dynamic of convergence across Brazilian states. This probably explains at least part of the persistence in regional income disparities in Brazil.

\footnotetext{
${ }^{7}$ If we follow the strategy suggested by Anselin and Rey (1991), from the test for spatial dependence of Table 1, we will chose the model with the related test presenting the highest level of significance; in this case, the LM robust spatial error.
} 
Table 2 - Results of the spatial dependence models

\begin{tabular}{lcc|cc|cc}
\hline Model specification & AIC & SC & $\beta$ & p-values & $\begin{array}{c}\text { Spatial } \\
\text { coefficients } \\
\lambda, \rho, \phi\end{array}$ & $\begin{array}{c}\text { p- } \\
\text { values }\end{array}$ \\
\hline Spatial error (ML) & -162.601 & -160.163 & -0.010 & $(0.007)$ & 0.409 & $(0.036)$ \\
Spatial lag (ML) & -159.142 & -155.485 & -0.007 & $(0.033)$ & 0.259 & $(0.217)$ \\
Cross regressive (OLS) & -159.887 & -156.230 & -0.012 & $(0.021)$ & 0.004 & $(0.214)$ \\
Convergence rate, spatial error (ML) estimation $=0.0006$ & & & \\
\hline
\end{tabular}

Obs.: The convergence rate is obtained using $\theta=\ln (\beta+1) /-\mathrm{k}$, where $\mathrm{k}$ is the number of years in the period.

In order to obtain a quantitative measure of the relative importance of the spatial dependence of the residuals, and to stress the strong results we have found, we have introduced in equation (2) a shock to the error term for the state of Goiás (geographically located in the center of the country) and used the maximum likelihood estimates of the coefficients of this equation. As Map 5 shows, the largest impact occurs in the state of Goiás itself and in its neighbors. For Goiás, the growth rate over the period is $144 \%$ higher than without the shock. It is interesting to note that even states that are not neighbors to Goiás present a significant change in the rate of growth, such as the rich states of São Paulo and Rio de Janeiro. This evidence implies that it is even more important in the Brazilian case to understand the origins of such influences. 


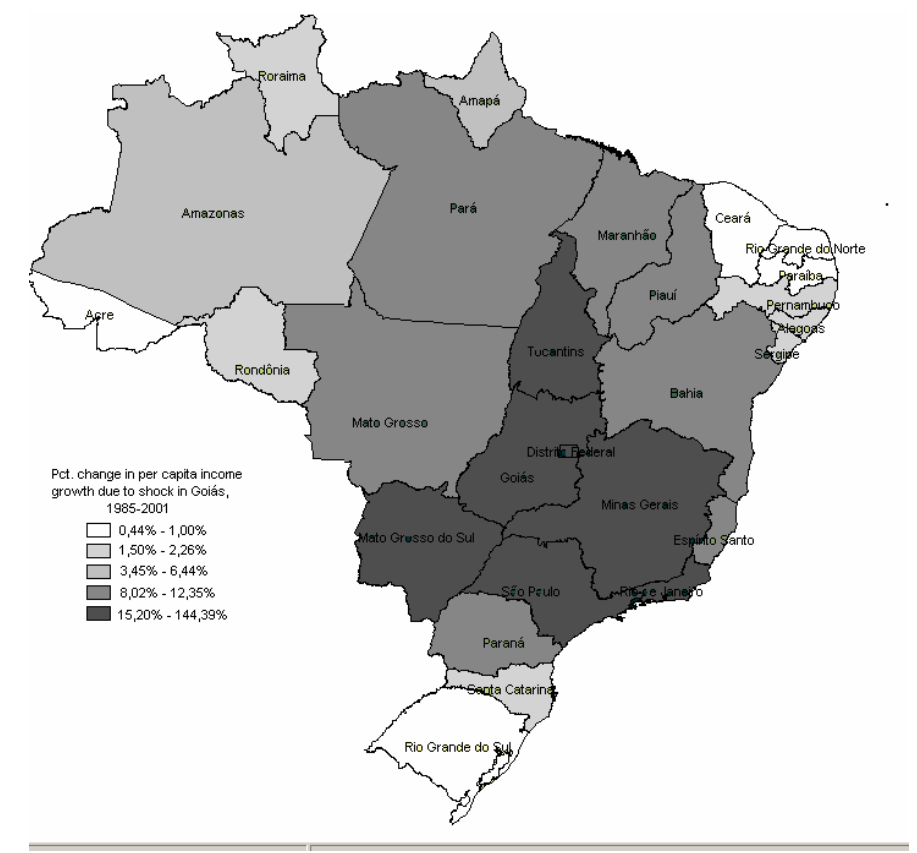

Map 5 - Percentage change in per capita income.

Growth rate due to shock in Goiás state, 1985-2001

\section{Sources of spatial correlation and conditional convergence}

The correct specification of the convergence equation for the Brazilian states has to consider the spatial correlation in the error term, since, as it was noted, it has a strong impact in the convergence process. Given this strong result, we have investigated if, even after conditioning on other important variables that could affect per capita income growth, there is any kind of spatial dependence.

As pointed out by Lall and Shalizi (2003), the spatial correlation of the residuals could potentially be attributed to unmeasured or unobserved spatial correlated factors, such as social, cultural or climatic. In order to account for that, we have included in the equation two variables commonly considered in explaining economic growth: human capital level and the share of manufacturing in the work force of states. As for human capital, we follow the suggestion of Mankiw, Romer and Weil (1992), that the dynamic of human capital accumulation should be incorporated in the Solow model in order to 
obtain a better empirical performance ${ }^{8}$. Moreover, as showed by Banhabib and Spiegel (1994), human capital might have an important role in the growth dynamics, not only as an additional factor in the production function, but also indicating the possibility of technical progress absorption. The share of manufacturing provides information on the preexisting economic structure, a factor that could explain spatially correlated economic performance.

Two points are important to highlight about these variables. First, by including them, we are investigating conditional convergence, that is, the existence of spatial dependence even when states are converging to their particular steady states. Second, as can be noted in maps 6 and 7, these variables present a clear pattern of geographical or regional distribution. This implies that they can be potentially correlated with factors connected to the ones responsible for the transmission of shocks.

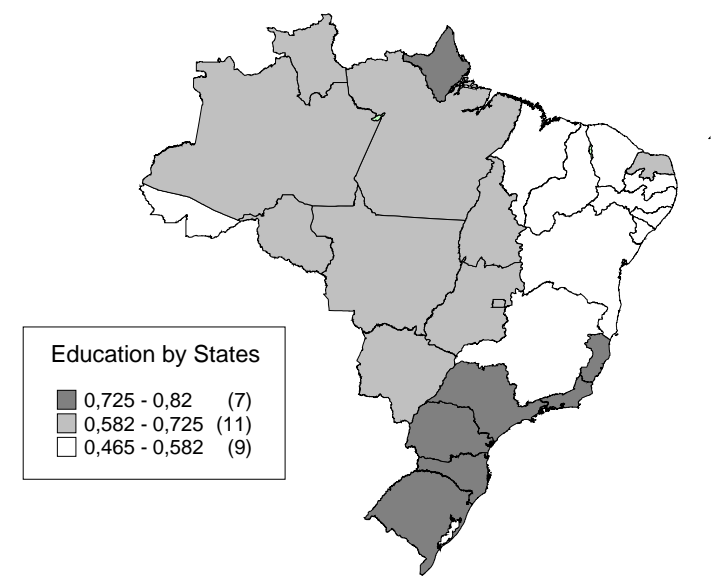

Map 6 - Education level by States, 1985.

(A composite of illiteracy and enrollment rates)

\footnotetext{
${ }^{8}$ Education is introduced in two different ways: a composite of illiteracy and enrollment rates, as a proxy for investments in human capital, and the number of years of schooling in 1985, a proxy for initial stock of human capital. The results for education coefficient are the same in both cases; the other coefficients do not change substantively either.
} 


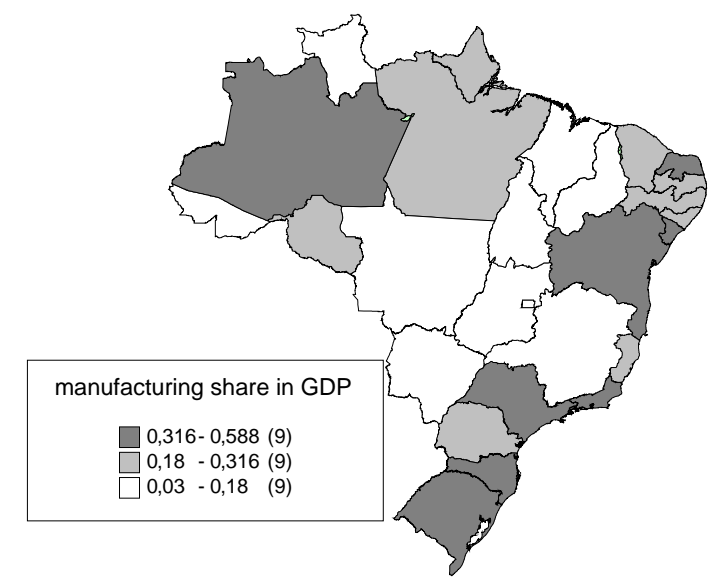

Map 7 - Manufacturing share in States, 1985.

We have estimated the following specification:

$$
g=\alpha+\beta y_{0}+X \gamma+\varepsilon,
$$

In which $\mathrm{X}$ is a matrix comprising the two new independent variables, education levels in the beginning of the period, and the manufacturing share in this year, and $\gamma$ is a vector of the two corresponding parameters. By including state specific variables in the equation we have changed the analysis from absolute to conditional convergence. This also provides information on the channels of spatial dependence in per capita income growth, which is our focus of interest.

Table 3 presents the results of the estimation of equation (5). First, we note that all the coefficients are significant (5\%), and present the expected signs. The convergence coefficient is now higher, and the initial level of education and the initial manufacturing share present positive effects on per capita income growth. More important, the three tests indicate that the hypothesis of spatial dependence is rejected, at very high significance level. In other words, there is no sign of the existence of any kind of spatial dependence. This important result is confirmed by estimating models (2) and (3) with the two additional variables of equation (5), as shown in Table 4. As it can be seen, neither of the two spatial coefficients is now significant. Moreover, the coefficients of the 
remaining variables present similar values as in comparison to the OLS results. It is important to point out that this last result was obtained after conditioning on variables that have very strong regional or geographic patterns across Brazilian states. In fact, this implies that we have found potential channels for the existence of strong spatial dependence in the process of convergence of per capita income of Brazilian states.

\section{Conclusions}

In this paper we have provided evidence on the importance of location for the growth of per capita income of Brazilian states over the period 1985-2001. Brazil is an interesting case study, for its regional income disparities are among the highest and more persistent in the world. We have first considered the potential spatial effects on the traditional unconditional convergence equation. We have then offered evidence on the possible channels through which these spatial effects exert their influences.

The study shows strong evidence of spatial dependence, and that regional inequality reduction occurred simultaneously with increasing spatial autocorrelation. This is an interesting result, for it strongly differs from those of Rey and Montouri (1999), for American states. It indicates either a reduction in inequality in the vicinity of rich states, 
Table 3 - Conditional model - OLS estimation

\begin{tabular}{|c|c|c|c|c|}
\hline & Conditional & p-values & Unconditional & p-values \\
\hline$\alpha$ & 0.102 & $(0.001)$ & 0.075 & $(0.018)$ \\
\hline$\beta$ & -0.018 & $(0.001)$ & -0.008 & $(0.041)$ \\
\hline Education & 0.008 & $(0.033)$ & - & \\
\hline Manufacturing & 0.105 & $(0.047)$ & - & \\
\hline Adjusted $\mathrm{R}^{2}$ & 0.3416 & & 0.1682 & \\
\hline AIC & -165.278 & & -160.098 & \\
\hline Convergence rate & 0.0011 & & 0.0005 & \\
\hline \multicolumn{5}{|c|}{ Diagnosis for spatial dependence } \\
\hline Moran’s I & 0.499 & $(0.617)$ & 1.938 & $(0.052)$ \\
\hline Robust LM (error) & 0.033 & $(0.855)$ & 2.662 & $(0.102)$ \\
\hline Robust LM (lag) & 0.061 & $(0.804)$ & 1.726 & $(0.188)$ \\
\hline \multicolumn{5}{|c|}{ Diagnosis for heteroskedascticity } \\
\hline Breusch-Pagan test & 1.714 & $(0.633)$ & 0.0126 & $(0.910)$ \\
\hline Koenker-Bassett test & 1.648 & $(0.648)$ & 0.0164 & $(0.898)$ \\
\hline
\end{tabular}

Obs.: $p$ - value in parenthesis. The convergence rate is obtained using $\theta=\ln (\beta+1) /-k$, in which $\mathrm{k}$ is the number of years in period.

Table 4 - Conditional convergence - OLS and ML estimations

\begin{tabular}{l|cc|cc|cc}
\hline & $\begin{array}{c}\text { Spatial error } \\
\text { (ML) }\end{array}$ & $\begin{array}{c}\mathbf{p}^{-} \\
\text {value }\end{array}$ & $\begin{array}{c}\text { Spatial lag } \\
\text { (ML) }\end{array}$ & $\begin{array}{c}\mathbf{p}^{-} \\
\text {value }\end{array}$ & OLS & $\begin{array}{c}\mathbf{p}^{-} \\
\text {value }\end{array}$ \\
\hline$\alpha$ & 0.101 & $(0.000)$ & 0.104 & $(0.000)$ & 0.102 & $(0.001)$ \\
$\beta$ & -0.018 & $(0.000)$ & -0.018 & $(0.004)$ & -0.018 & $(0.001)$ \\
Education & 0.009 & $(0.009)$ & 0.009 & $(0.013)$ & 0.008 & $(0.033)$ \\
Manufacturing & 0.108 & $(0.015)$ & 0.106 & $(0.023)$ & 0.105 & $(0.047)$ \\
Spatial coefficients $\zeta, \lambda$ & -0.079 & $(0.746)$ & -0.025 & $(0.905)$ & & \\
AIC & -165.340 & & -163.287 & & 165.278 & \\
SC & -160.464 & & -157.193 & & 160.402 & \\
\hline
\end{tabular}

or diminishing inequality among poor states, a result strongly supported by the finding of Mossi et all. (2003), and Magalhaes et all. (2005). The analysis of local indicators of spatial association confirmed that conclusion, showing the existence of two geographical clusters, one of low income states in the Northeast and North regions, and another of rich states in the Southeast and South regions. Over the entire period, only two middle-income states, out of 25 , changed their status by joining the richest cluster; the number of states in the low income group remained the same. 
The analysis of convergence suggests that the effects of spatial shocks in the dynamic of growth in Brazil are stronger than those observed in the USA. The low value for the convergence coefficient, in conjunction with the strong influence of shocks in the residuals, indicate the existence of a very sensitive dynamic of convergence across Brazilian states, what helps explaining the well documented persistence of regional income disparities in Brazil. A shock introduced in a particular state indicates that the largest impact occurs in that same state and in its neighbors, but that other non-neighbor states also present a significant change in their growth rates. This evidence implies that it is necessary, in the Brazilian case, to understand the origins of such influences.

We have then investigated if, after conditioning on other important variables that could affect growth, there still is spatial dependence. We have added to the equation the educational level and the share of manufacturing in each state at the beginning of the period. By doing so, we have investigated the existence of spatial dependence when states are converging to their particular steady states. The estimated convergence coefficient was higher, and the variables indicating the different steady states were significant, with similar coefficients as in comparison to the OLS results.

The most important result, however, is that spatial dependence has disappeared. The addition of the initial educational levels and manufacturing shares of the states, variables which present a clear pattern of geographical or regional distribution, have accounted for the previously found spatial dependence. We have thus identified two potential channels through which the strong spatial dependence in the process of convergence of per capita income of Brazilian states occurs.

\section{References}

Ades A F, Chua H B (1997) “Thy neighbor’s curse: regional political instability and economic growth”. Journal of Economic Growth 2: 279-304

Ades A F, Glaeser E L (1994) "Evidence on growth, increasing returns and the extent of the market”. NBER, Working Paper No. 4714

Adserà A (2000) "Sectoral spillovers and the price of land: a cost analysis". Regional Science and Urban Economics, 30: 565-585. 
Anselin L (1988) Spatial econometrics: methods and models. Kluwer Academic, Dordrecht.

Anselin L, Rey S (1991) "Properties of testes for spatial dependence in linear regression models”. Geographical Analysis 23(2):112-131, April

Arrow K (1962) “The economic implications of learning by doing”. Review of Economic Studies, June

Attfield C L F, Cannon E S, Demery D, Duck N W (2000) "Economic growth and geographical proximity”. Economic Letters 68:109-12.

Azzoni, C R (2001) “Economic growth and regional economic inequality in Brazil”. The Annals of Regional Science 35:133-52

Azzoni, C R, Andrade A S (2005) “The tertiary sector and regional inequality in Brazil”. Région et Development, $\mathrm{n}^{\mathrm{0}}$ 21:155-172

Azzoni C R, Menezes-Filho N A, Menezes T A, Silveira-Neto R (2000) “Geography and income convergence among Brazilian states”. Inter-American Development Bank (Research Network Working Papers; R-395)

Azzoni C R, Menezes-Filho N A, Menezes, T A (2005) “Opening the convergence black box: measurement problems and demographic aspects”. In R. Kanbur and A. Venables (Ed.) Spatial Inequality and Development, UNU-Wider Studies in Development Economics, Oxford Academic Press, p. 61-74

Azzoni C R, Servo L S (2002) "Education, cost of living and regional wage inequality in Brazil”. Papers in Regional Science 81(2):157-175 April

Azzoni, C R, Silveira-Neto, R. (2005) "Decomposing regional growth: labor force participation rates, structural changes, and sectoral factor reallocation”. The Annals of Regional Science 39:1-19

Baer, W. (2001) The Brazilian Economy, $5^{\text {th }}$ Edition, Praeger

Barro R J, Sala-i-Martin X (1991). “Convergence across States and Regions” Brooking Papers of Economic Activities, no.1: 107-182.

(1995) Economic growth. McGraw-Hill, Singapore.

(1997) “Technological diffusion, convergence, and growth”. Journal of Economic Growth 2: 1-26

Benhabib J, Spiegel M M (1994) "The role of human capital in economic development: evidence from aggregate cross-country data”. Journal of Monetary Economics 34:143-173

Braun J (1993) Essays on economic growth and migration. Ph.D. Dissertation, Harvard University.

Case A (1992) "Neighborhood influence and technological change”. Regional Science and Urban Economics 22: 491-508

Chua H (1993) "Regional spillovers and economic growth”. Yale University, Economic Growth Center, Discussion Paper No.700, September. 
Easterly W, Levine R (1995) “Africa’s growth tragedy: a retrospective”, 1960-89, World Bank, Policy Research Working Paper No.1503

Eaton J, Kortum S (1994) “International patenting and technological diffusion”. NBER Working Paper No.1503.

(1996) “Trade in ideas: patenting and productivity in the OECD”, Journal of International Economics 40: 251-278

Eaton J, Tamura A (1994) "Bilateralism and regionalism in Japanese and U. S. Trade and foreign Direct Investment Patterns”. Journal of Japanese and International Economies 8: 478-510.

Frankel J A, Romer D (1996) “Trade and growth: an empirical investigation”. NBER Working Paper No. 5476.

Frankel J A, Wei S (1993) “Trade blocs and currency blocs”. NBER Paper No. 4335

Goodfriend M, McDermott J (1998) "Industrial development and the convergence question”. American Economic Review 88(5):1277-1289 December

Griliches Z (1992) “The search for R\&D spillovers”. Scandinavian Journal of Economics 94: $29-48$

Jaffe A, Trajtenberg M, Henderson R (1993) “Geographic localization of knowledge spillovers as evidenced by patent citations”. Quarterly Journal of Economics 3: 577-598

Lucas R (1988) “On the mechanics of economic development”. Journal of Monetary Economics 22:3-42

Lall, S.L., Shalizi, Z. (2003) “Location and growth in Brazilian Northeast”, Journal of Regional Science, v.43, n.4: 663-681.

Magalhães A, Hewings G, Azzoni C R (2005) "Spatial dependence and regional convergence in Brazil”. Investigaciones Regionales, 6:5-20

Mankiw N G, Romer D, Weil D (1992) "A contribution to the empirics of economic growth”. Quarterly Journal of Economics 107: 407-437

Moreno R, Trehan B (1997) “Location and the growth of nations”. Journal of Economic Growth 2: 399-418

Mossi M B, Aroca P, Fernández I J, Azzoni CR (2003) "Growth dynamics and space in Brazil”, International Review of Regional Science, Vol $26 \mathrm{~N}^{\mathrm{o}}$ 3, 393-418

Murphy K, Shekeifer A, Vishny R W (1989a) "Income distribution, market size and industrialization”. Quarterly Journal of Economics 104:537-564 97:1003-1026

Rey S R (2001) “Spatial empirics for economic growth and convergence”. Geographical Analysis 33:195-214

Rey S R, Montouri B D (1999) "US regional income convergence: A spatial econometric perspective”. Regional Studies 33: 143-156 
Romer P (1986) “Increasing returns and long run growth”. Journal of Political Economy 94:1002-1037

Shankar R, Shah A (2003) "Bridging the economic divide within nations: a scorecard on the performance of regional development policies in reducing regional income disparities”, World Development, 31:8, 1421-1441

\section{Appendix 1. Data}

State data on per capita income for 25 Brazilian states $^{9}$, covering the period 19852001, came from the regional accounts developed by IBGE, the Brazilian official data agency (http://www.ibge.gov.br). For investments in human capital we used the education index developed by UNDP/IPEA, which is defined as the average of the illiteracy rate and the combined enrollment rate. For proxies for the stock of human capital, we used the average number of years in school for the population as a whole, and for the employed population. Both education variables were obtained from a national survey of a sample of households (PNAD), which is produced by IBGE.

\footnotetext{
${ }^{9}$ The state of Tocantins was added to Goiás, since the former was part of the latter in the initial years of the series. The Federal District (Brasília) was excluded from the sample, due to the strong and erratic influence of the federal government wage policy on its per capita income.
} 